\title{
Steady exercise improves hand grip and leg muscle strength in hemodialysis patients
}

\author{
Ran-hui Cha*, Geum Sil Lee \\ Department of Internal Medicine, National Medical Center, Seoul, Korea
}

Sarcopenia due to chronic inflammation and biochemical disturbances in chronic kidney disease is severer and more prevalent in hemodialysis (HD) patients. We longitudinally evaluated the hand grip strength (HGS) and leg muscle strength (LMS) and evaluated the role of exercise in muscle strength in $\mathrm{HD}$ patients. We screened (January, $n=127$ ) and followed up (June, $n=110$ and December 2020, $n=104$ ). HGS and LMS at single center by using digital hand and leg dynamometer. HGS $(24.2 \mathrm{~kg}$ vs. $15.5 \mathrm{~kg})$ and LMS (32.8 kg vs. $22.5 \mathrm{~kg})$ were better in men $(P<0.001$ and $P<0.001$, respectively). Older patients ( $\geq 60$ years) showed decreased LMS than others in women $(P=0.01)$. Patients who performed steady home- or hospital-based exercise showed marginally higher HGS (23.1 kg vs. $19.8 \mathrm{~kg}, P=0.07$ ) and significantly higher LMS $(33.7 \mathrm{~kg}$ vs. $25.9 \mathrm{~kg}, P=0.004)$. Steady exercise improved LMS throughout the

\section{INTRODUCTION}

Sarcopenia is characterized by loss of muscle mass and strength and a decreased quality of life (QoL), and is associated with protein-energy wasting in chronic kidney disease (CKD) and end-stage renal disease (ESRD) patients (Moon et al., 2015). Sarcopenia is also associated with functional decline, increased risk of falling, and increased mortality (Goisser et al., 2015; Hanna et al., 2020). Depression associated with sarcopenia in dialysis patients also leads to decreased survival (Farrokhi et al., 2014). The prevalence of sarcopenia in Asian countries ranged from $5.5 \%$ to $25.7 \%$ (Chen et al., 2020), while the prevalence of sarcopenia in hemodialysis (HD) patients varies from 21 to $68 \%$ depending on the methodology and demographics (Slee et al., 2020). There are approximately 80,000 (1,497.6 patients/million population) ESRD patients receiving $\mathrm{HD}$ in Korea and the number of patients has been in- study period ( $30.3 \mathrm{~kg}$ vs. $33.2 \mathrm{~kg}$ from Jan to Jun $2020, P=0.004 ; 30.3 \mathrm{~kg}$ vs. $34.2 \mathrm{~kg}$ from Jan to Dec 2020, $P=0.014)$. Multiple linear regression analysis proved steady exercise was independently associated with better HGS and LMS. Steady exercise showed greater impact on LMS in male patients with longer HD vintage ( $\geq 44$ months) and on HGS in younger male patients with shorter HD vintage ( $<44$ months). Steady exercise was an important determinant of muscle strength in $\mathrm{HD}$ patients. We need to encourage patients to steadily perform regular home- or group-exercise before sarcopenia develops.

Keywords: Exercise, Hand grip strength, Hemodialysis, Leg muscle strength
${ }^{*}$ Corresponding author: Ran-hui Cha (D) https://orcid.org/0000-0003-2783-2600 Department of Internal Medicine, National Medical Center, 245 Eulji-ro, Jung-gu, Seoul 04564, Korea

Email: reginaprayer@gmail.com

Received: October 27, 2021 / Accepted: November 21, 2021 creasing by $5 \%-8 \%$ annually.

CKD-associated catabolic changes, including chronic low-grade inflammation, can explain the severe manifestation of sarcopenia in CKD patients (Fahal, 2014). Inflammatory cytokines and inactivity-mediated destruction of protein homeostasis result in the catabolic destruction of structural and functional proteins, resulting in skeletal muscle wasting (Lenk et al., 2010). Accumulation of uremic toxins in muscle cells and following superoxide production and the upregulation of inflammatory cytokines such as tumor necrosis factor- $\alpha$, interleukin- 6 (IL-6), and transforming growth factor- $\beta$ induced muscle wasting through myostatin and atrogin-1 (Enoki et al., 2016). Mitochondrial dysfunction of skeletal muscles in $\mathrm{CKD}$, which is mediated by metabolic alterations, i.e., upregulation of antioxidative responses and downregulation of energy-generation pathways, is also considered a cause of the loss of muscle mass and exercise capacity (Adey et al., 2000; Sato et al., 
2016; Tamaki et al., 2014; Yazdi et al., 2013). These changes can be aggravated by the catabolic effect of HD procedure itself (Ikizler, 2005).

There have been many approaches to treat sarcopenia, but only exercise and nutritional support have proven to be effective as prevention and treatment strategies for sarcopenia (Morley, 2018). Protein and amino acid supplementation improved body composition, physical function, and nutritional status by increasing serum albumin levels and body mass index (BMI), while it reduced inflammatory markers in dialysis patients (Caetano et al., 2017; Liu et al., 2018; Tomayko et al., 2015). Resistance training during protein restriction counteracted impaired muscle cell metabolism (Cupisti et al., 2014). We previously reported that exercise was one of the most important determinants of muscle strength in HD patients (Cha et al., 2021).

The Kidney Disease Outcome Quality Initiative (K/DOQI) and European guidelines recommend that nephrologists counsel and encourage dialysis patients to increase physical activity (Fouque et al., 2007; K/DOQI Workgroup, 2005). However, providing exercise therapy to patients who are unable to perform conventional dynamic training due to position limitations, hemodynamic instability during dialysis, low motivation, or fatigue is a major challenge (McGregor et al., 2018). HD patients, especially elderly patients, reported low levels of physical activity, which is associated with poor physical function and frailty (Johansen et al., 2000).

In this study, we longitudinally evaluated hand grip strength (HGS) and leg muscle strength (LMS) in patients receiving HD and tried to consolidate the role of exercise as a prevention and treatment strategy.

\section{MATERIALS AND METHODS}

\section{Study design}

This study was a longitudinal study conducted at a single HD center. We screened in January $2020(\mathrm{n}=127)$ and followed up in June $2020(n=110)$ and in December $2020(n=104)$. HGS (opposite the fistula side) and LMS (both sides) by using digital hand and leg dynamometers (T.K.K. 5401 and 5710e/5715, Takei Scientific Instruments Co., Ltd., Niigata, Japan).

A digital hand dynamometer (T.K.K. 5401, Takei Scientific Instruments Co., Ltd.) was used to measure the sitting position HGS (opposite the fistula side). Participants were seated, with the shoulder along the body and no rotation, $90^{\circ}$ elbow flexion, and neutral flexion. Supporting pads or tables were applied. Participants were encouraged to grasp strongly 2 times at intervals of 1 to $2 \mathrm{~min}$, and the greater $\mathrm{HGS}$ was used in the analysis. A digital leg dynamometer (T.K.K. 5710e/5715, Takei Scientific Instruments Co., Ltd.) was used to measure the LMS of the knee joint extension muscles (both sides) as directed in the manufacturer's instructions. Participants were seated, with $90^{\circ}$ of knee flexion, and measurements were repeated 2 times at intervals of 1 to $2 \mathrm{~min}$. The greatest LMS was used in the analysis.

We collected data on demographics (age, sex); anthropometrics (height, dry weight); medical histories, including diabetes, hypertension, coronary artery disease, cerebrocardiovascular (CCV) disease, peripheral artery occlusive disease/interventions, malignancies, and chronic liver diseases; cause of ESRD; and HD vintage. We also collected biochemical data, including dialysis efficiency $(\mathrm{Kt} / \mathrm{V})$, hemoglogin, blood urea nitrogen/serum creatinine (SCr), calcium/ phosphorus, total $\mathrm{CO}_{2}$, highly sensitive $\mathrm{C}$-reactive protein (hs-CRP), intact parathyroid hormone, and iron/total iron-binding capacity.

We evaluated the exercise status. We interviewed regular homebased exercise as follows: (1) Do you regularly exercise at home? (2) Which type of exercise do you do? (3) How many hours do you exercise at once? (4) How many times do you exercise during a week? (5) Do you feel tiredness or exhaustion during the exercise? The type, duration, and intensity of exercise were variable. Therefore, we only considered whether regular exercise was performed, i.e., at least 3 times a week. We also considered participation in hospital-based intradialytic resistance exercise using a latex band. Patients in the intradialytic exercise (IDE) program performed resistance exercise after the initiation of dialysis on one's own volition, and an assigned physician assistant helped patients in terms of the number of repetitions, intensity, and duration.

\section{Ethics statement}

The study was approved by the institutional review boards (NMC-2021-04-054). Written informed consent was acquired from the participants.

\section{Statistical analysis}

Continuous variables are expressed as the mean \pm standard deviation (for variables with normal distributions) or medians (25th75th percentiles) (for variables with nonnormal distributions), and categorical variables are expressed as number (\%). The baseline characteristics, biochemical results, and muscle strength results were compared using the $\chi^{2}$ test, Student $t$-test/Mann-Whitney $U$-test, paired $t$-test/Wilcoxon signed-rank test, or analysis of variance/Kruskal-Wallis tests, as appropriate. Multiple regression analysis was used to identify significant factors related to muscle 
strength by using variables with $P$-values below 0.05 . All statistical analyses were performed with IBM SPSS Statistics ver. 20.0 (IBM Co., Armonk, NY, USA). $P$-values were two-sided and were considered significant at $P<0.05$.

\section{RESULTS}

\section{Baseline characteristics}

The demographic and biochemical characteristics of the participants at each measurement are summarized in Table 1. In December 2020, the mean age was 62.1 years, and $73.2 \%$ of the patients were male. Diabetes was the cause of kidney failure in $49.6 \%$ of the patients, and the median HD vintage was 44 months. A total of $49.0 \%$ of patients reported that they performed regular homebased exercise, and $15.4 \%$ of patients regularly participated in IDE. The proportion of patients who performed regular home- or hospital-based exercise decreased from January to December. Mean HGS and LMS were 21.5 and $29.8 \mathrm{~kg}$, respectively.

\section{HGS and LMS}

Table 2 compares HGS and LMS between the general population (Korea National Health and Nutrition Examination VI-3 survey [Yoo et al., 2017] and Takei Scientific Instruments Co., Ltd. presented) and HD patients in December 2020. The HGS of HD patients was approximately 15\%-50\% less than that of the general population in almost all age groups in both males and females. The LMS of HD patients started to decrease after the age of 70 in both males and females, and it was approximately $20 \%-40 \%$ less than that of the general population.

HGS and LMS showed good correlation $(r=0.658, P<0.001)$. HGS (24.2 kg vs. $15.5 \mathrm{~kg}$ ) and LMS (32.8 kg vs. $22.5 \mathrm{~kg}$ ) were greater in males $(P<0.001$ and $P<0.001$, respectively) than in females. Muscle strength was greater in males irrespective of age, although LMS in younger patients was not different between males and females. Older patients ( $\geq 60$ years) had less LMS than younger patients in females $(P=0.01)$, but HGS in both sexes and LMS in males did not differ by age $(P=0.23, P=0.10$, and

Table 1. Demographic and biochemical characteristics of participants at each time points

\begin{tabular}{|c|c|c|c|}
\hline Variable & Jan $2020(n=112)$ & June $2020(n=110)$ & $\operatorname{Dec} 2020(n=104)$ \\
\hline Age (yr) & $62.6 \pm 12.7$ & $63.1 \pm 12.58$ & $62.1 \pm 12.50$ \\
\hline Male sex & $82(73.2)$ & $88(72.1)$ & $93(73.2)$ \\
\hline Cause of ESRD, diabetic nephropathy & $56(50.0)$ & $58(47.9)$ & $63(49.6)$ \\
\hline Regular home-based exercise & $88(78.6)$ & $72(64.9)$ & $51(49.0)$ \\
\hline Hospital-based intradialytic resistance exercise & $33(29.5)$ & $44(39.6)$ & $16(15.4)$ \\
\hline Home- and/or hospital-based exercise & $91(81.2)$ & $65(65.7)$ & $55(52.9)$ \\
\hline Dry weight $(\mathrm{kg})$ & $61.6 \pm 10.6$ & $60.9 \pm 10.83$ & $60.8 \pm 11.07$ \\
\hline Body mass index $\left(\mathrm{kg} / \mathrm{m}^{2}\right)$ & $22.7 \pm 3.3$ & $22.6 \pm 3.19$ & $21.8 \pm 4.94$ \\
\hline HD vintage (mo) & $34(11-62)$ & $37(13-66)$ & $44(20-73)$ \\
\hline Dialysis efficiency (Kt/N) & $1.43 \pm 0.19$ & $1.47(1.33-1.59)$ & $1.42(1.32-1.57)$ \\
\hline Hemoglobin (g/dL) & $10.45(9.9-11.1)$ & $10.2(9.6-10.7)$ & $10.4(9.7-10.9)$ \\
\hline Blood urea nitrogen (mg/dL) & $59(48-77)$ & $62.8 \pm 17.93$ & $68.3 \pm 20.06$ \\
\hline Serum creatinine (mg/dL) & $9.27 \pm 2.52$ & $9.66 \pm 2.674$ & $9.9(8.7-11.4)$ \\
\hline Serum albumin (g/dL) & $4.0(3.8-4.3)$ & $4.1(3.9-4.3)$ & $4.0 \pm 0.46$ \\
\hline Serum calcium (mg/dL) & $8.8 \pm 0.6$ & $8.89 \pm 0.545$ & $8.7 \pm 0.62$ \\
\hline Serum phosphorus (mg/dL) & $4.6 \pm 1.3$ & $4.21 \pm 1.074$ & $4.4(3.5-5.3)$ \\
\hline total $\mathrm{CO}_{2}$ (meq/L) & $19.6 \pm 3.7$ & $20(12-31)$ & $21.6 \pm 3.41$ \\
\hline hs-CRP (mg/dL) & $0.14(0.05-0.48)$ & $0.11(0.5-4.7)$ & $0.50(0.14-0.64)$ \\
\hline Intact PTH (pg/mL) & $146.1(77.8-238.7)$ & $134.8(57.2-221.2)$ & $196.7(107.9-323.6)$ \\
\hline $\operatorname{Iron}(\mu \mathrm{g} / \mathrm{dL})$ & $63(47-79)$ & $172(54-256)$ & $109(58-206)$ \\
\hline $\mathrm{TIBC}(\mu \mathrm{g} / \mathrm{dL})$ & $229(187-263)$ & $200(86.5-271)$ & 184 (69-273) \\
\hline Transferrin saturation (\%) & $28.9(21.0-38.8)$ & $48.4(25.5-307.7)$ & $43.1(26.6-293.1)$ \\
\hline Hand grip strength (opposite to fistula side, kg) & $21.8(17.0-29.2)$ & $19.8 \pm 8.13$ & $21.5 \pm 8.09$ \\
\hline Leg muscle strength (greater side, kg) & $26.9(20.3-33.5)$ & $28.4(21-38)$ & $29.8 \pm 12.06$ \\
\hline
\end{tabular}

Values are presented as mean \pm standard deviation, number $(\%)$, or median (25th-75th percentile).

ESRD, end-stage renal disease; HD, hemodialysis; hs-CRP, highly sensitive C-reactive protein; PTH, parathyroid hormone; TIBC, total iron-binding capacity. 
Table 2. Comparison of mean hand grip and leg muscle strength in December 2020 between general population and hemodialysis patients

\begin{tabular}{|c|c|c|c|c|c|c|c|c|}
\hline \multirow{3}{*}{ Age } & \multicolumn{4}{|c|}{ Hand grip strength (kg), mean (n) } & \multicolumn{4}{|c|}{ Leg muscle strength $(\mathrm{kg})$, mean (n) } \\
\hline & \multicolumn{2}{|c|}{ General population } & \multicolumn{2}{|c|}{ Hemodialysis patients } & \multicolumn{2}{|c|}{ General population } & \multicolumn{2}{|c|}{ Hemodialysis patients } \\
\hline & Male* & Female $^{*}$ & Male & Female & Male $^{\dagger}$ & Female $^{\dagger}$ & Male & Female \\
\hline $20-29$ & $41.3(329)$ & $24.4(339)$ & & & $35.1(7)$ & $21.8(6)$ & & \\
\hline 30-39 & $44.4(298)$ & $26.2(416)$ & $19.8(1)$ & $22.4(3)$ & $33.6(23)$ & $22.7(28)$ & $19.9(1)$ & $29.3(3)$ \\
\hline $40-49$ & $43.7(367)$ & $28.6(464)$ & $28.4(9)$ & $17.2(4)$ & $32.4(24)$ & $23.2(19)$ & $33.0(9)$ & $28.8(3)$ \\
\hline $50-59$ & $40.6(423)$ & $24.7(548)$ & $24.5(18)$ & $12.7(3)$ & $32.0(26)$ & $22.5(20)$ & $34.8(20)$ & $25.8(3)$ \\
\hline $60-69$ & $37.8(330)$ & $23.3(405)$ & $25.9(19)$ & $16.2(8)$ & $32.7(46)$ & $25.9(75)$ & $37.7(18)$ & $25.0(7)$ \\
\hline 70-79 & $31.2(204)$ & $20.2(252)$ & $18.8(10)$ & $13.3(10)$ & $36.2(81)$ & $26.1(91)$ & $28.7(9)$ & $16.1(9)$ \\
\hline$\geq 80$ & $26.9(56)$ & $16.7(191)$ & $22.2(8)$ & $12.0(1)$ & $36.2(10)$ & $19.7(6)$ & $22.4(8)$ & $14.4(1)$ \\
\hline
\end{tabular}

*Each value means the average of age-specific hand grip strength using data from the Korea National Health and Nutrition Examination Survey (KNHANES) VI-3 (2015) survey. 'Takei Scientific Instruments Co., Ltd., Niigata, Japan presented. 'Participants from Department of Physical Education and Department of Public Health, Gifu University, Japan'.

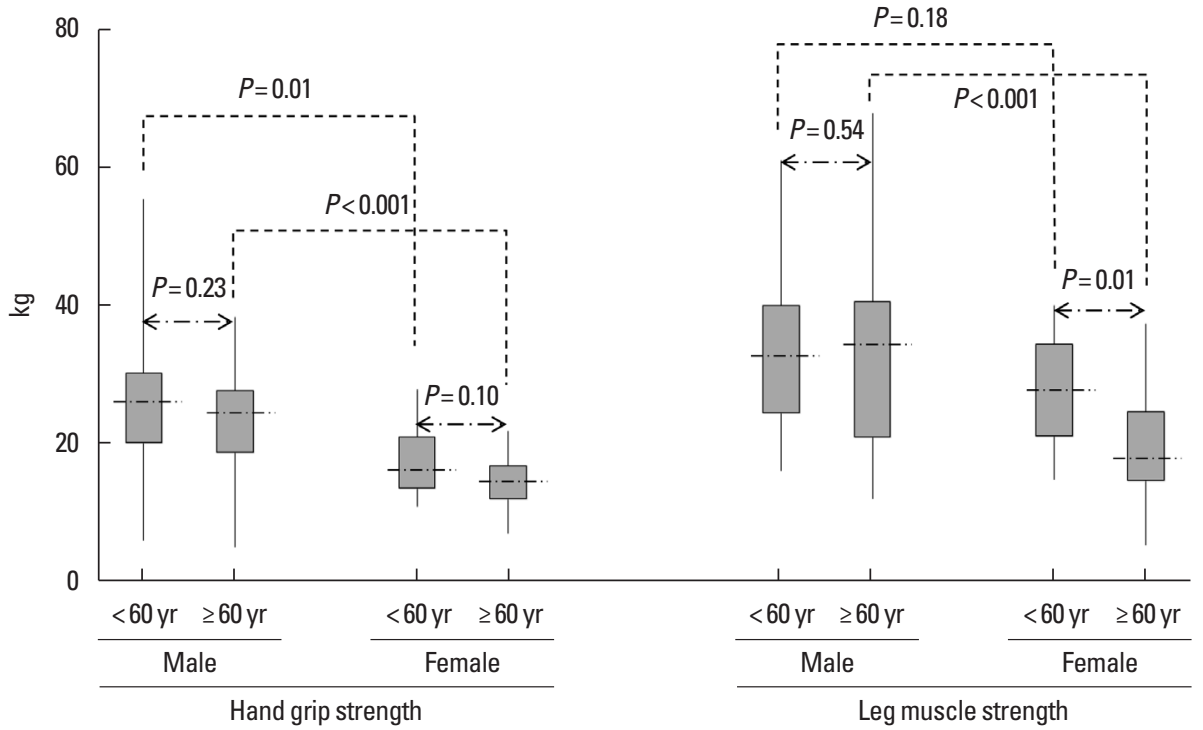

Fig. 1. Hand grip and leg muscle strength in December 2020 according to age and sex. Whiskers go from minimum to maximum values with 1 st and 3rd quartile box points. The horizontal dotted line represents the median level.

$P=0.54$, respectively) (Fig. 1). Dry weight $(r=0.432, P<0.001$ and $r=0.364, P<0.001$, respectively), $\mathrm{SCr}(r=0.259, P=0.012$ and $r=0.334, P=0.001$, respectively), and serum albumin $(r=$ $0.220, P=0.033$ and $r=0.282, P=0.007$, respectively) were positively correlated with HGS and LMS. Age $(r=-0.27, P=0.008$ and $r=-0.283, P=0.007$, respectively $)$ and $\mathrm{Kt} / \mathrm{V}(r=-0.238, P=$ 0.009 and $r=-0.243, P=0.02$, respectively) were negatively correlated with HGS and LMS. HD vintage $(r=-0.231, P=0.025)$ and hs-CRP ( $r=-0.23, P=0.02)$ were negatively correlated only with HGS.

The presence of diabetes, hypertension, CCV disease, peripheral artery obstructive disease, malignancy, and chronic liver disease did not affect LMS. However, HGS was lower in patients with CCV disease than in those without CCV disease $(19.2 \mathrm{~kg}$ vs. $23.2 \mathrm{~kg}$, $P=0.016)$.

\section{Relationship between exercise and muscle strength}

We gave one point to each type of exercise at each time point (a total of 6 points). Patients with high exercise scores (3-6) showed marginally higher LMS (31.8 kg vs. $26.5 \mathrm{~kg}, P=0.06$ ), but HGS did not show statistical significance $(22.5 \mathrm{~kg}$ vs. $19.9 \mathrm{~kg}, P=0.17)$. Patients who performed steady home- or hospital-based exercise from January to December 2020 showed marginally higher HGS (23.1 kg vs. $19.8 \mathrm{~kg}, P=0.07)$ and significantly higher LMS (33.7 kg vs. $25.9 \mathrm{~kg}, P=0.004$ ) (Fig. 2).

High exercise scores (3-6) showed an improving trend of LMS 

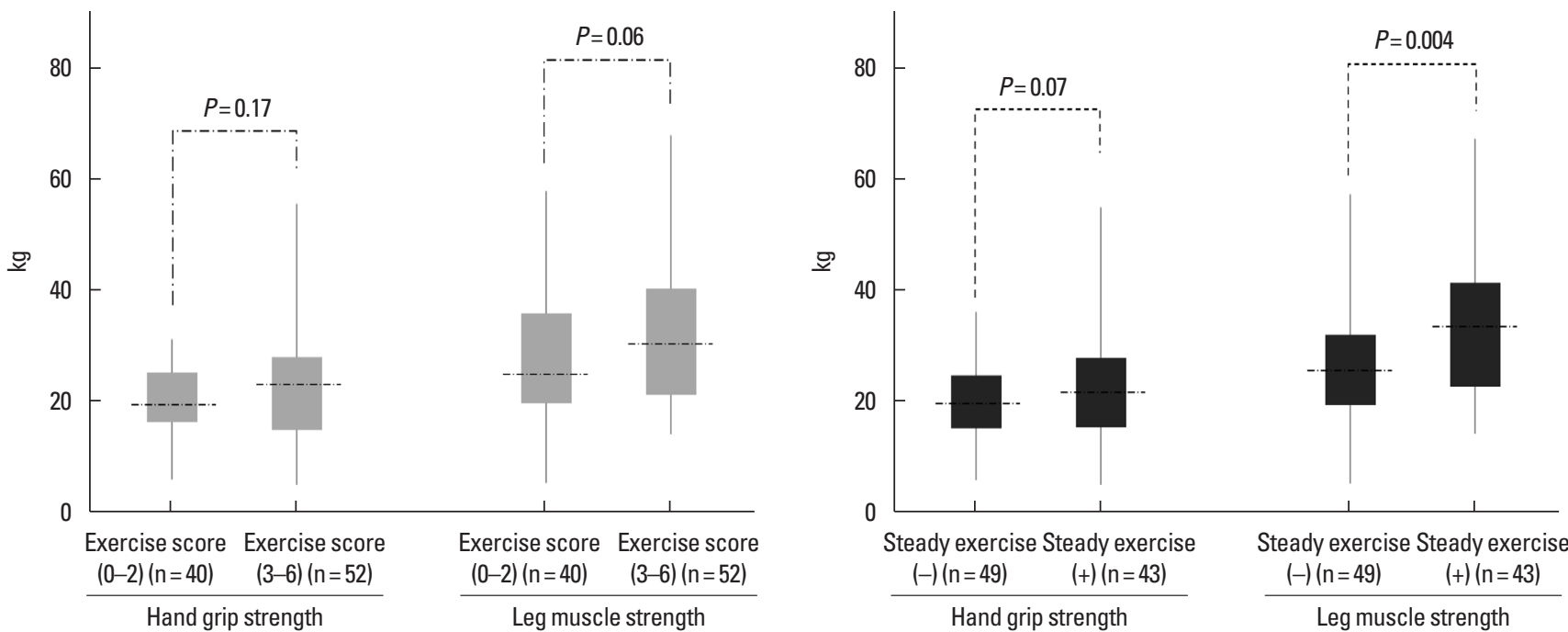

Fig. 2. Hand grip and leg muscle strength in December 2020 according to exercise score and steady exercise. Whiskers go from minimum to maximum values with 1 st and 3rd quartile box points. The horizontal dotted line represents the median level.
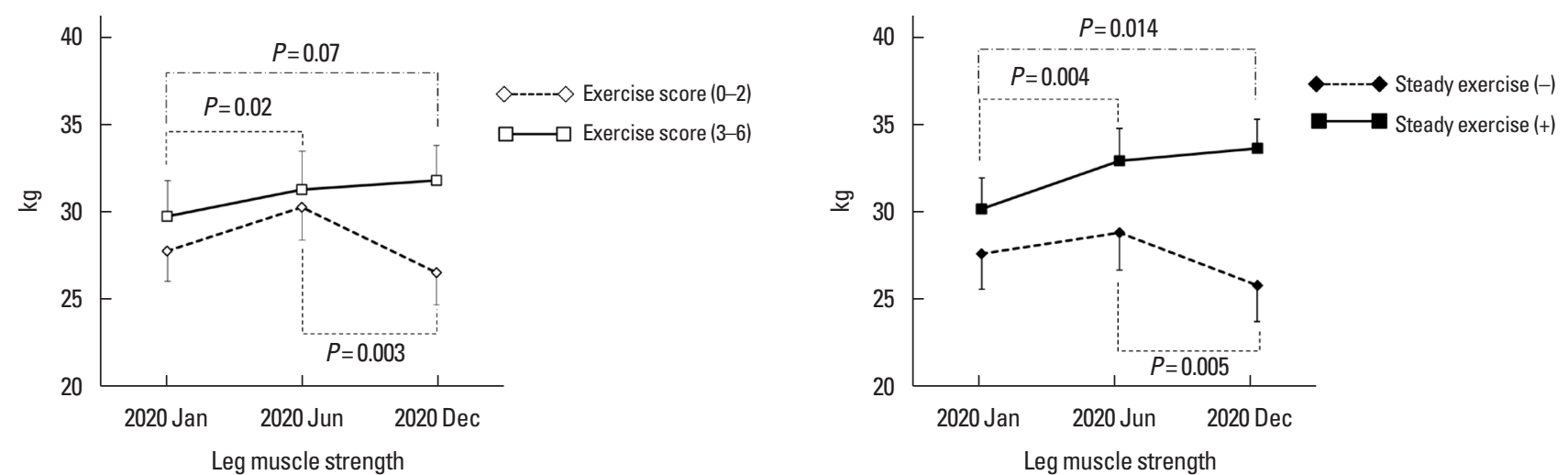

Fig. 3. Progress of leg muscle strength according to exercise score and steady exercise. Data were expressed as mean and standard error.

from January to December 2020 (29.8 kg vs. $32.0 \mathrm{~kg}$ from January to June $2020, P=0.02 ; 30.4 \mathrm{~kg}$ vs. $32.5 \mathrm{~kg}$ from January to December 2020, $P=0.07)$. Steady exercise improved LMS from January to December 2020 (30.3 kg vs. $33.2 \mathrm{~kg}$ from January to June $2020 ; P=0.004,30.3 \mathrm{~kg}$ vs. $34.2 \mathrm{~kg}$ from January to December 2020, $P=0.014$ ) Patients with low exercise scores (0-2) or patients who did not exercise steadily showed a significant decrease in LMS between June and December $2020(32.1 \mathrm{~kg}$ vs. $27.5 \mathrm{~kg}, P=0.003$ and $30.0 \mathrm{~kg}$ vs. $26.4 \mathrm{~kg}, P=0.005$, respectively) (Fig. 3). LMS changes from January to December 2020 were $3.2 \pm 7.72$ and $-1.7 \pm 8.57 \mathrm{~kg}$ in patients who did and did not perform steady exercise, respectively $(P=0.01)$.

\section{Factors related to muscle strength}

Multiple linear regression analysis proved that a high exercise scores (3-6) or steady exercise were factors associated with better HGS and LMS (Table 3). High exercise scores (3-6) showed a greater impact on LMS in older ( $\geq 60$ years) male patients with longer HD vintage ( $\geq 44$ months) and on HGS in male patients with shorter HD vintage ( $<44$ months). Steady exercise showed a greater impact on LMS in male patients with longer HD vintage ( $\geq 44$ months) and on HGS in younger male patients with shorter HD vintage ( $<44$ months). SCr also influenced LMS, while age, dry weight, $\mathrm{HD}$ vintage, and hs-CRP affected HGS.

\section{DISCUSSION}

This study showed a good correlation between HGS and LMS, and both HGS and LMS were greater in men than in women. Age had a greater impact on LMS in women. HD patients who exer- 
Table 3. Multiple linear regression analysis of the factors related with hand grip and leg muscle strength in December 2020

\begin{tabular}{|c|c|c|c|c|c|c|c|c|}
\hline \multirow{3}{*}{ Variable } & \multicolumn{4}{|c|}{ Exercise score from Jan to Dec 2020 (3-6) (reference: 0-2) } & \multicolumn{4}{|c|}{ Steady exercise (yes) (reference: no) } \\
\hline & \multicolumn{2}{|c|}{ Hand grip strength } & \multicolumn{2}{|c|}{ Leg muscle strength } & \multicolumn{2}{|c|}{ Hand grip strength } & \multicolumn{2}{|c|}{ Leg muscle strength } \\
\hline & $\begin{array}{c}\text { Standardized } \\
\text { coefficient }\end{array}$ & $P$-value & $\begin{array}{c}\text { Standardized } \\
\text { coefficient }\end{array}$ & $P$-value & $\begin{array}{c}\text { Standardized } \\
\text { coefficient }\end{array}$ & $P$-value & $\begin{array}{c}\text { Standardized } \\
\text { coefficient }\end{array}$ & $P$-value \\
\hline Female sex & -0.482 & $<0.001$ & -0.345 & 0.001 & -0.490 & $<0.001$ & -0.358 & $<0.001$ \\
\hline Age (yr) & -0.209 & 0.029 & -0.195 & 0.061 & -0.194 & 0.039 & -0.178 & 0.067 \\
\hline Exercise status & 0.185 & 0.030 & 0.268 & 0.006 & 0.219 & 0.010 & 0.367 & $<0.001$ \\
\hline HD vintage (mo) & -0.239 & 0.006 & - & - & -0.231 & 0.007 & - & - \\
\hline Dry weight (kg) & 0.307 & 0.011 & 0.199 & 0.139 & 0.326 & 0.006 & 0.234 & 0.066 \\
\hline Dialysis efficiency (Kt/N) & 0.114 & 0.347 & 0.04 & 0.763 & 0.127 & 0.289 & 0.056 & 0.653 \\
\hline Serum albumin (g/dL) & 0.138 & 0.130 & 0.175 & 0.076 & 0.139 & 0.121 & 0.163 & 0.082 \\
\hline Serum creatinine (mg/dL) & 0.033 & 0.712 & 0.201 & 0.043 & 0.028 & 0.753 & 0.186 & 0.047 \\
\hline hs-CRP (mg/dL) & -0.259 & 0.005 & - & - & -0.242 & 0.008 & - & - \\
\hline
\end{tabular}

Units of age and $\mathrm{HD}$ vintage are years and months, respectively.

hs-CRP, highly sensitive C-reactive protein; SC, standardized coefficient.

cised more (high exercise scores and steady exercise) had better muscle strength. In particular, steady exercise significantly improved LMS. Dry weight, serum albumin, and $\mathrm{SCr}$ were positively correlated with HGS and LMS. Kt/V showed a negative correlation with HGS and LMS. HD vintage negatively correlated with HGS. Sex and exercise were the most important determinants of both HGS and LMS in HD patients. Male patients, patients with a shorter vintage of HD for HGS, and those with a longer vintage of $\mathrm{HD}$ for LMS benefitted more from exercise. SCr also influenced LMS, while age, dry weight, HD vintage, and hsCRP affected HGS.

In this study, HD patients who exercised more (high exercise scores and steady exercise) had better muscle strength. In particular, steady exercise significantly improved LMS. Exercise was one of the most important determinants of both HGS and LMS in HD patients even after multivariable adjustment. Inactivity induces glucocorticoid, myostatin, NF- $\mathrm{kB}$, and reactive oxygen species, which accelerate protein degradation (Fahal, 2014). Exercise is an anabolic-based strategy and improves muscle size, the protein synthesis rate, neuromuscular function, insulin sensitivity, and inflammation associated with increased insulin-stimulated glucose and amino acid transport (Goisser et al., 2015; Jung et al., 2018).

Resistance training restored muscle cell metabolism during protein restriction (Cupisti et al., 2014). Resistance training together with protein or amino acid supplementation showed beneficial effects on muscle mass and/or muscle function. Regular exercise also showed positive effects on nutritional markers such as serum albumin, prealbumin, and energy intake (Cupisti et al., 2014). In addition, IDE combined with oral or parenteral nutrition enhanced amino acid uptake and the protein content in the muscles of HD patients, indicating an improved anabolic effect of nutritional supplementation (Majchrzak et al., 2008). A review pointed that exercise should be prescribed at the right patient (a patient who can tolerate and benefit from the exercise), right time (when the patient's stamina is the highest), and right dose (beneficial exercise intensity but not ineffective or even harmful) (Ikizler, 2019).

Physical inactivity is an important clinical problem among CKD and dialysis patients (Cupisti et al., 2014). Both the K/DOQI and European guidelines emphasize the role of nephrologists in encouraging dialysis patients to increase physical activity, such as aerobic, resistance, coordination, and flexibility exercises (Fouque et al., 2007; K/DOQI Workgroup, 2005). However, we often fail to encourage HD patients to perform exercise because patients' motivation to exercise is lacking.

IDE can be a convenient option to ensure compliance and reduce uncomfortable dialysis-related symptoms such as restless legs and cramping (Kirkman et al., 2014a). IDE can enhance or replace physical exercise in frail and exercise-hesitant HD patients. Intradialytic cardiovascular and strengthening exercise improved oxygen uptake, inflammation, arterial compliance, muscle strength, physical activity, and psychosocial functioning. These types of exercise also improved the efficiency of dialysis $(\mathrm{Kt} / \mathrm{V})$ and solute clearance, QoL, depression, and the hospitalization rate (Heiwe et al., 2014; Johansen and Painter, 2012; Kirkman et al., 2014b; Koh et al., 2010; Moraes et al., 2014; Rhee et al., 2019; Salhab et al., 2019).

Intradialytic neuromuscular electrical stimulation (NMES) can also be a good option to enhance muscle strength and physical 
functioning as well as exercise compliance in HD patients, especially exercise-hesitant patients. Several studies have proven the effectiveness of NMES in HD patients. Intradialytic NMES improved muscular strength, muscle cross-sectional area, cardiorespiratory reserves $\left(\mathrm{VO}_{2}\right.$ peak, $\mathrm{VO}_{2}$ anaerobic threshold), functional capacity, and QoL (Dobsak et al., 2012; McGregor et al., 2018; Simó et al., 2015; Suzuki et al., 2018).

An increased catabolic state, including persistent inflammation, metabolic acidosis, hormonal imbalance, and physical inactivity, leads to excessive muscle wasting (Carrero et al., 2013; Hanna et al., 2020; Hyun et al., 2017). ATP-dependent ubiquitin-proteasome (UPS) proteolysis is the major cause of increased skeletal muscle degradation in CKD. Inflammation and metabolic acidosis play a major role in activating the UPS (Fahal, 2014). In this study, hs-CRP affected HGS after adjustment for multiple variables. This is concordant with previous reports. Inflammation markers, including IL-6 and CRP, were negatively correlated with muscle mass in dialysis patients (Kaizu et al., 2003). Nuclear factor-kappa B and insulin/insulin growth factor-1 were associated with protein catabolism (Fahal, 2014).

In this study, serum albumin, dry weight, and $\mathrm{SCr}$ were positively correlated with HGS and LMS, while Kt/V showed a negative correlation with HGS and LMS. SCr influenced LMS even after adjustment for multiple variables. Malnutrition is considered a nontraditional cardiovascular risk factor in dialysis patients. The typical dietary protein intake recommendation for ESRD patients is $1.2 \mathrm{~g} / \mathrm{kg} /$ day (Kidney Disease Improving Global Outcomes [KDIGO], 2013; K/DOQI Workgroup, 2005). Some experts even recommended a dietary protein intake of more than $1.8 \mathrm{~g} / \mathrm{kg} /$ day in dialysis patients because they do not have to prevent CKD progression and are in a hypercatabolic state due to dialysis itself (Bauer et al., 2013). The Korea National Health and Nutrition Examination Survey 2012-2016 data showed that 40.5\% and $59.9 \%$ of males and females older than 75 years had protein intakes that were less than the estimated average requirements. And many patients receiving dialysis maintain the protein-restricted diet recommended for predialysis CKD patients. The positive correlation between serum albumin and muscle strength is in line with previous reports (Caetano et al., 2017; Liu et al., 2018; Tomayko et al., 2015).

$\mathrm{SCr}$ can be a good surrogate marker of muscle mass in dialysis patients with no or minimal residual renal function, and several studies reported better survival in patients with higher BMI and SCr than in patients with lower BMI and SCr (Canaud et al., 2014; Park et al., 2013; Patel et al., 2013) The positive and negative correlations of dry weight and $\mathrm{Kt} / \mathrm{V}$ with muscle strength, respectively, imply the same meaning because small patients usually have high levels of $\mathrm{Kt} / \mathrm{V}$.

In this study, male patients, patients with a shorter vintage of HD for HGS, and patients with a longer vintage of HD for LMS benefitted more from exercise. In addition, $\mathrm{SCr}$ and dry weight, which reflect muscle mass, were also important in determining muscle strength. This may imply that patients with reduced habitual physical activity (older age) and a considerable amount of muscle mass (male sex, shorter duration of HD for HGS, and longer duration of HD for LMS) can benefit from exercise.

This study has several limitations, including the absence of body composition data, inaccurate measurement of home-based exercise (i.e., exercise was self-reported and the information on the type, duration, and strength of exercise was incomplete), and the lack of information on dietary and nutritional status.

In conclusion, steady exercise was an important determinant of muscle strength in HD patients. We need to encourage patients to steadily perform regular home- or hospital-based group- exercise before sarcopenia develops. We also have to introduce new feasible forms of exercise for $\mathrm{HD}$ patients.

\section{CONFLICT OF INTEREST}

No potential conflict of interest relevant to this article was reported.

\section{ACKNOWLEDGMENTS}

The authors received no financial support for this article.

\section{REFERENCES}

Adey D, Kumar R, McCarthy JT, Nair KS. Reduced synthesis of muscle proteins in chronic renal failure. Am J Physiol Endocrinol Metab 2000; 278:E219-E225.

Bauer J, Biolo G, Cederholm T, Cesari M, Cruz-Jentoft AJ, Morley JE, Philips S, Sieber C, Stehle P, Teta D, Visvanathan R, Volpi E, Boirie Y. Evidencebased recommendations for optimal dietary protein intake in older people: a position paper from the PROT-AGE Study Group. J Am Med Dir Assoc 2013;14:542-559.

Caetano C, Valente A, Silva FJ, Antunes J, Garagarza C. Effect of an intradialytic protein-rich meal intake in nutritional and body composition parameters on hemodialysis patients. Clin Nutr ESPEN 2017;20:29-33.

Canaud B, Granger Vallée A, Molinari N, Chenine L, Leray-Moragues H, 
Rodriguez A, Chalabi L, Morena M, Cristol JP. Creatinine index as a surrogate of lean body mass derived from urea $\mathrm{Kt} / \mathrm{V}$, pre-dialysis serum levels and anthropometric characteristics of haemodialysis patients. PLoS One 2014;9:e93286.

Carrero JJ, Stenvinkel P, Cuppari L, Ikizler TA, Kalantar-Zadeh K, Kaysen G, Mitch WE, Price SR, Wanner C, Wang AY, ter Wee P, Franch HA. Etiology of the protein-energy wasting syndrome in chronic kidney disease: a consensus statement from the International Society of Renal Nutrition and Metabolism (ISRNM). J Ren Nutr 2013;23:77-90.

Cha RH, Lee GS, Yoo JY, Rhee OB, Jeon YD. Hand grip and leg muscle strength in hemodialysis patients and its determinants. J Korean Med Sci 2021;36:e76.

Chen LK, Woo J, Assantachai P, Auyeung TW, Chou MY, lijima K, Jang HC, Kang L, Kim M, Kim S, Kojima T, Kuzuya M, Lee JSW, Lee SY, Lee WJ, Lee Y, Liang CK, Lim JU, Lim WS, Peng LN, Sugimoto K, Tanaka T, Won CW, Yamada M, Zhang T, Akishita M, Arai H. Asian Working Group for Sarcopenia: 2019 consensus update on sarcopenia diagnosis and treatment. J Am Med Dir Assoc 2020;21:300-307.

Cupisti A, D'Alessandro C, Fumagalli G, Vigo V, Meola M, Cianchi C, Egidi MF. Nutrition and physical activity in CKD patients. Kidney Blood Press Res 2014;39:107-113.

Dobsak P, Homolka P, Svojanovsky J, Reichertova A, Soucek M, Novakova M, Dusek L, Vasku J, Eicher JC, Siegelova J. Intra-dialytic electrostimulation of leg extensors may improve exercise tolerance and quality of life in hemodialyzed patients. Artif Organs 2012;36:71-78.

Enoki Y, Watanabe H, Arake R, Sugimoto R, Imafuku T, Tominaga Y, Ishima Y, Kotani S, Nakajima M, Tanaka M, Matsushita K, Fukagawa M, Otagiri M, Maruyama T. Indoxyl sulfate potentiates skeletal muscle atrophy by inducing the oxidative stress-mediated expression of myostatin and atrogin-1. Sci Rep 2016;6:32084.

Fahal IH. Uraemic sarcopenia: aetiology and implications. Nephrol Dial Transplant 2014;29:1655-1665.

Farrokhi F, Abedi N, Beyene J, Kurdyak P, Jassal SV. Association between depression and mortality in patients receiving long-term dialysis: a systematic review and meta-analysis. Am J Kidney Dis 2014;63:623635.

Fouque D, Vennegoor M, ter Wee P, Wanner C, Basci A, Canaud B, Haage P, Konner K, Kooman J, Martin-Malo A, Pedrini L, Pizzarelli F, Tattersall J, Tordoir J, Vanholder R. EBPG guideline on nutrition. Nephrol Dial Transplant 2007;22(Suppl 2):ii45-ii87.

Goisser S, Kemmler W, Porzel S, Volkert D, Sieber CC, Bollheimer LC, Freiberger E. Sarcopenic obesity and complex interventions with nutrition and exercise in community-dwelling older persons - a narrative review. Clin Interv Aging 2015;10:1267-1282.

Hanna RM, Ghobry L, Wassef O, Rhee CM, Kalantar-Zadeh K. A practi- cal approach to nutrition, protein-energy wasting, sarcopenia, and cachexia in patients with chronic kidney disease. Blood Purif 2020;49: 202-211.

Heiwe S, Jacobson SH. Exercise training in adults with CKD: a systematic review and meta-analysis. Am J Kidney Dis 2014;64:383-393.

Hyun YY, Lee KB, Han SH, Kim YH, Kim YS, Lee SW, Oh YK, Chae DW, Ahn C. Nutritional status in adults with predialysis chronic kidney disease: KNOW-CKD Study. J Korean Med Sci 2017;32:257-263.

Ikizler TA. Effects of hemodialysis on protein metabolism. J Ren Nutr 2005;15:39-43.

Ikizler TA. Intradialytic nutrition and exercise: convenience versus efficacy. Kidney Int 2019;96:549-552.

Johansen KL, Chertow GM, Ng AV, Mulligan K, Carey S, Schoenfeld PY, Kent-Braun JA. Physical activity levels in patients on hemodialysis and healthy sedentary controls. Kidney Int 2000;57:2564-2570.

Johansen KL, Painter P. Exercise in individuals with CKD. Am J Kidney Dis 2012;59:126-134.

Jung HW, Kim SW, Kim IY, Lim JY, Park HS, Song W, Yoo HJ, Jang HC, Kim K, Park Y, Park YJ, Yang SJ, Lee HJ, Won CW. Protein intake recommendation for Korean older adults to prevent sarcopenia: expert consensus by the Korean Geriatric Society and the Korean Nutrition Society. Ann Geriatr Med Res 2018;22:167-175.

Kaizu Y, Ohkawa S, Odamaki M, Ikegaya N, Hibi I, Miyaji K, Kumagai H. Association between inflammatory mediators and muscle mass in long-term hemodialysis patients. Am J Kidney Dis 2003;42:295-302.

K/DOQI Workgroup. K/DOQI clinical practice guidelines for cardiovascular disease in dialysis patients. Am J Kidney Dis 2005;45(4 Suppl 3): S1-S153.

Kidney Disease Improving Global Outcomes (KDIGO). KDIGO 2012 clinical practice guideline for the evaluation and management of chronic kidney disease. Chapter 3: management of progression and complications of CKD. Kidney Int Suppl 2013;3:73-90.

Kirkman DL, Edwards DG, Lennon-Edwards S. Exercise as an adjunct therapy in chronic kidney disease. Renal Nutr Forum 2014a;33:1-8.

Kirkman DL, Mullins P, Junglee NA, Kumwenda M, Jibani MM, Macdonald JH. Anabolic exercise in haemodialysis patients: a randomised controlled pilot study. J Cachexia Sarcopenia Muscle 2014b;5:199-207.

Koh KP, Fassett RG, Sharman JE, Coombes JS, Williams AD. Effect of intradialytic versus home-based aerobic exercise training on physical function and vascular parameters in hemodialysis patients: a randomized pilot study. Am J Kidney Dis 2010;55:88-99.

Lenk K, Schuler G, Adams V. Skeletal muscle wasting in cachexia and sarcopenia: molecular pathophysiology and impact of exercise training. J Cachexia Sarcopenia Muscle 2010;1:9-21.

Liu PJ, Ma F, Wang QY, He SL. The effects of oral nutritional supplements 
in patients with maintenance dialysis therapy: a systematic review and meta-analysis of randomized clinical trials. PLoS One 2018;13:e0203706.

Majchrzak KM, Pupim LB, Flakoll PJ, Ikizler TA. Resistance exercise augments the acute anabolic effects of intradialytic oral nutritional supplementation. Nephrol Dial Transplant 2008;23:1362-1369.

McGregor G, Ennis S, Powell R, Hamborg T, Raymond NT, Owen W, Aldridge N, Evans G, Goodby J, Hewins S, Banerjee P, Krishnan NS, Ting SMS, Zehnder D. Feasibility and effects of intra-dialytic low-frequency electrical muscle stimulation and cycle training: a pilot randomized controlled trial. PLoS One 2018;13:e200354.

Moon SJ, Kim TH, Yoon SY, Chung JH, Hwang HJ. Relationship between stage of chronic kidney disease and sarcopenia in Korean aged 40 years and older using the Korea National Health and Nutrition Examination Surveys (KNHANES IV-2, 3, and V-1, 2), 2008-2011. PLoS One 2015; 10:e0130740.

Moraes C, Marinho SM, da Nobrega AC, de Oliveira Bessa B, Jacobson LV, Stockler-Pinto MB, da Silva WS, Mafra D. Resistance exercise: a strategy to attenuate inflammation and protein-energy wasting in hemodialysis patients? Int Urol Nephrol 2014;46:1655-1662.

Morley JE. Treatment of sarcopenia: the road to the future. J Cachexia Sarcopenia Muscle 2018;9:1196-1199.

Park J, Jin DC, Molnar MZ, Dukkipati R, Kim YL, Jing J, Levin NW, Nissenson AR, Lee JS, Kalantar-Zadeh K. Mortality predictability of body size and muscle mass surrogates in Asian vs white and African American hemodialysis patients. Mayo Clin Proc 2013;88:479-486.

Patel SS, Molnar MZ, Tayek JA, Ix JH, Noori N, Benner D, Heymsfield S, Kopple JD, Kovesdy CP, Kalantar-Zadeh K. Serum creatinine as a marker of muscle mass in chronic kidney disease: results of a crosssectional study and review of literature. J Cachexia Sarcopenia Muscle 2013;4:19-29.

Rhee SY, Song JK, Hong SC, Choi JW, Jeon HJ, Shin DH, Ji EH, Choi EH, Lee J, Kim A, Choi SW, Oh J. Intradialytic exercise improves physical function and reduces intradialytic hypotension and depression in hemodialysis patients. Korean J Intern Med 2019;34:588-598.

Salhab N, Karavetian M, Kooman J, Fiaccadori E, El Khoury CF. Effects of intradialytic aerobic exercise on hemodialysis patients: a systematic review and meta-analysis. J Nephrol 2019;32:549-566.

Sato E, Mori T, Mishima E, Suzuki A, Sugawara S, Kurasawa N, Saigusa D, Miura D, Morikawa-Ichinose T, Saito R, Oba-Yabana I, Oe Y, Kisu K, Naganuma E, Koizumi K, Mokudai T, Niwano Y, Kudo T, Suzuki C, Takahashi N, Sato H, Abe T, Niwa T, Ito S. Metabolic alterations by indoxyl sulfate in skeletal muscle induce uremic sarcopenia in chronic kidney disease. Sci Rep 2016;6:36618.

Simó VE, Jiménez AJ, Oliveira JC, Guzmán FM, Nicolás MF, Potau MP, Solé AS, Gallego VD, González IT, de Arellano Serna MR. Efficacy of neuromuscular electrostimulation intervention to improve physical function in haemodialysis patients. Int Urol Nephrol 2015;47:17091717.

Slee A, McKeaveney C, Adamson G, Davenport A, Farrington K, Fouque D, Kalantar-Zadeh K, Mallett J, Maxwell AP, Mullan R, Noble H, O'Donoghue D, Porter S, Seres DS, Shields J, Witham M, Reid J. Estimating the prevalence of muscle wasting, weakness, and sarcopenia in hemodialysis patients. J Renal Nutr 2020;30:313-321.

Suzuki T, Ikeda M, Minami M, Matayoshi Y, Nakao M, Nakamurra T, Abo M. Beneficial effect of intradialytic electrical muscle stimulation in hemodialysis patients: a randomized controlled trial. Artif Organs 2018;42:899-910.

Tamaki M, Miyashita K, Wakino S, Mitsuishi M, Hayashi K, Itoh H. Chronic kidney disease reduces muscle mitochondria and exercise endurance and its exacerbation by dietary protein through inactivation of pyruvate dehydrogenase. Kidney Int 2014;85:1330-1339.

Tomayko EJ, Kistler BM, Fitschen PJ, Wilund KR. Intradialytic protein supplementation reduces inflammation and improves physical function in maintenance hemodialysis patients. J Renal Nutr 2015;25:276283.

Yazdi PG, Moradi H, Yang JY, Wang PH, Vaziri ND. Skeletal muscle mitochondrial depletion and dysfunction in chronic kidney disease. Int J Clin Exp Med 2013;6:532-539.

Yoo JI, Choi H, Ha YC. Mean hand grip strength and cut-off value for sarcopenia in Korean adults using KNHANES VI. J Korean Med Sci 2017; 32:868-872. 